\title{
Parameter uncertainty in HEC-RAS 1D CSU scour model
}

\author{
Praveen Rathod $^{1, *}$ and V. L. Manekar ${ }^{2}$ \\ Department of Civil Engineering, Sardar Vallabhbhai National Institute of Technology, Surat 395 007, India
}

The predictive capability of a model is dependent on the parameter uncertainty involved in it. This study examines the effect of predictive uncertainty and parameter sensitivity in the application of the wellknown HEC-RAS 1D hydrodynamic CSU (Colorado State University) scour prediction model. Correlationbased technique was used for carrying out the sensitivity analysis. Monte Carlo method was adopted for uncertainty quantification. The methodology suggested in the present study drastically improved the predictive capability of the model, by reducing the model error from $26.6 \%$ to $0.07 \%$. In general, it improved the predictive capability of any scour model when tested on 19 datasets.

Keywords: Hydrodynamic model, parameter uncertainty, scour, prediction, sensitivity analysis.

ESTIMATION of scour always remains a part of active research. Numerous scour predicting models are reported in the literature in different forms and with different considerations. Hydraulic structures like bridges are well known for their failure mostly due to scour. It has been reported that high vertical turbulence near the structure causes scour around the bridge pier $^{1}$. Scour at the bridge pier is formation of a hole around the structure due to flowing water ${ }^{2}$. Prolonged scouring exposes the foundation of a structure and leads to failure. Scour around the bridge pier depends on numerous parameters such as depth of flow, shape of the pier, size of the sediments, angle of attack and sediment characteristics ${ }^{3}$. The prevailing practices of determining total scour involves summing of individual components of the scour such as local scour (abutment and pier), contraction scour (mobile channel and clear water), and scour due to change in the geometry of the channel because of aggradation, degradation, channel lining and widening. There are numerous models reported in the literature for estimating the scour around a bridge pier for clear-water and live-bed conditions $^{2-8}$. Landers and Mueller ${ }^{9}$ carried out a comparative study on five models and reported that none of the selected models precisely estimates the depth of scour under measured conditions. A recent comparative study carried out on various scour models revealed that the

\footnotetext{
*For correspondence. (e-mail: praveenrathodsh03@gmail.com)
}

Colorado State University (CSU) model estimates scour depth reasonably well compared to other scour predicting models ${ }^{10}$. Johnson ${ }^{11}$ compared seven scour models and found that the Melville and Sutherland model overpredicted to a great extent than any other model. However, accounting sediment gradation in the Melville and Sutherland model reduced over-prediction. Also, it was concluded in the same study that, to apply the same model to other study areas, there is a need of good approximation for model parameters. This is possible either by experimentation or carrying out a number of trails. However, adopting any one of the above means for good approximation has disadvantages such as high computation cost, and being tedious and cumbersome in nature. The present study addresses the issue of good approximation for model parameters based on uncertainty quantification.

There are at least two types of uncertainties involved in the scour prediction models; one is parameter uncertainty and other is model uncertainty (epistemic). Uncertainty may be defined as quantification of doubt. Error in prediction occurs mostly due to improper selection of either a model or parameter values of the model. In the present study, scour model is considered as the CSU model, and it has been demonstrated that assigning parameter values with uncertainty greatly affects estimation of scour. Choosing parameter value from the given field situation is subjective and always leads to uncertainty. An estimate of the exact values or the range of parametric values within which scour prediction for the selected field becomes more accurate can be obtained by reducing uncertainty. It is not only for curtailing the laborious efforts, but also to ensure proper consideration of parametric values.

There are numerous methods reported in the literature for carrying out uncertainty analysis, viz. Monte Carlo $\operatorname{method}^{12,13}$, generalized likelihood uncertainty estimation $(\text { GLUE })^{14}$, model error analysis methods ${ }^{15}$ and methods based on fuzzy set theory ${ }^{16}$. Selection of the appropriate method for carrying out uncertainty analysis is an important step in improving model predictability. In general, selection of a method is dependent on the quantity and quality of available data. For example, Monte Carlo method which is a sampling-based method is used when quantity and quality of the data are not satisfactorily available ${ }^{12,13}$, whereas Bayesian methods are used when quantity and quality of the data are satisfactorily available ${ }^{17}$. In the present study, based on the decision 


\section{RESEARCH ARTICLES}

tree $^{18}$ given for selecting the uncertainty method, Monte Carlo method for quantification of parameter uncertainty is adopted. Hydrodynamic modelling is generally used to estimate hydraulic parameters. Hydrodynamic modelling was carried out in the present study using the Hydrologic Engineering Centre's River Analysis System (HEC-RAS) tool. This also has the capability of performing hydraulic analysis (estimation of scour depth) using the literature recommended CSU model. Uncertainty analysis was carried out for the CSU model parameters.

\section{Study area and data collection}

Orsang Aqueduct, at $22^{\circ} 15^{\prime} 33^{\prime \prime} \mathrm{N}$ and $73^{\circ} 42^{\prime} 36^{\prime \prime} \mathrm{E}$ is located on the Orsang river near Bodeli, Gujarat, India. Figure $1 a$ and $b$ shows the location map of Orsang Aqueduct, and relative scour around the pier of the Aqueduct during the year of commencement (1998) and the year of observation (2015) respectively.

The aqueduct has a length of $548 \mathrm{~m}$ across the Narmada river. In the present study, on-site recorded maximum scour depth around the bridge piers in 2015 was collected and used. The aqueduct was designed for the

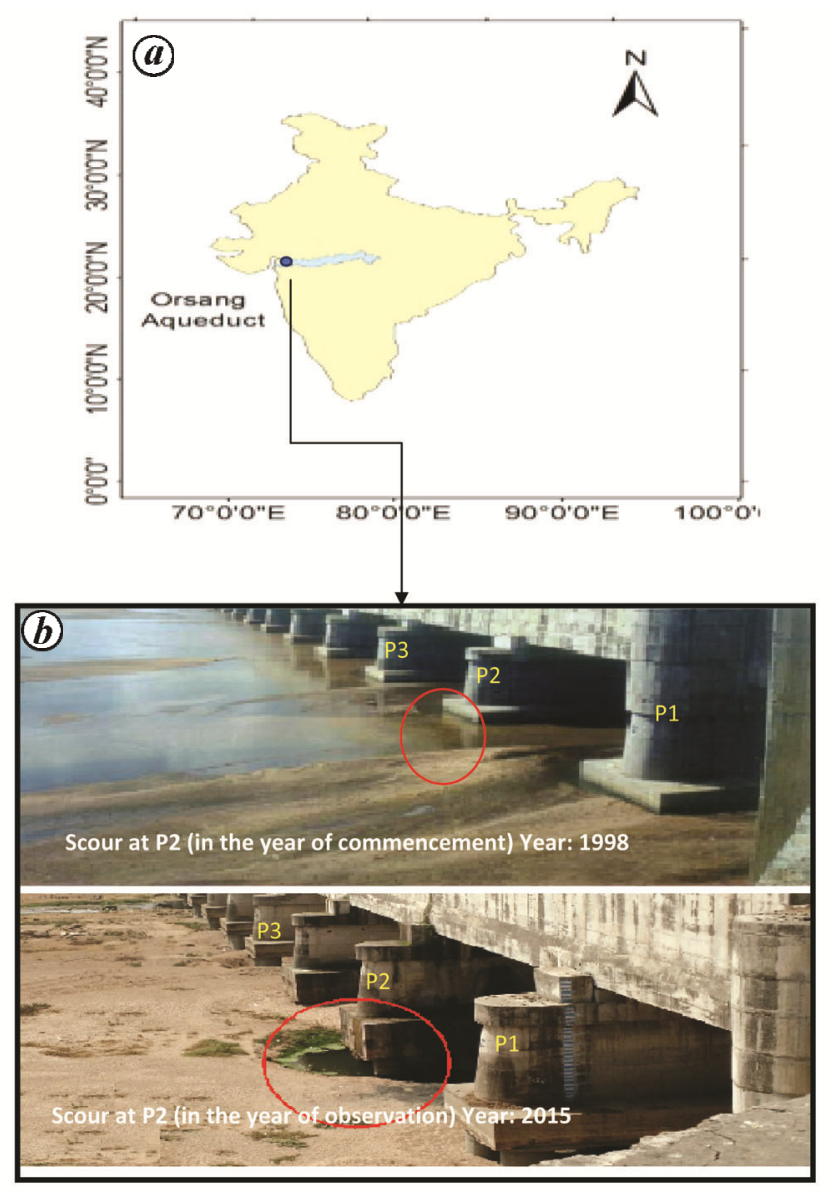

Figure 1. $\boldsymbol{a}$, Location map of Orsang Aqueduct. $\boldsymbol{b}$, Relative position of scour at P2 of Orsang Aqueduct during 1998 and 2015. maximum probable floods of $12,063 \mathrm{~m}^{3} / \mathrm{sec}$. There are 26 piers across the riverbed with round-shaped nose having dimensions of $2.5 \mathrm{~m} \times 80.8 \mathrm{~m} \times 4 \mathrm{~m}(W \times L \times H)$, in which height $(H)$ varies between 4 and $4.5 \mathrm{~m}$ based on the elevation along the cross section of river. In the present study, the second pier (P2) from the right-hand side was considered for uncertainty analysis (Figure $1 \mathrm{~b}$ ). The length of span provided was $20.3 \mathrm{~m}$ centre-to-centre and canal discharge rate was $1129 \mathrm{~m}^{3} / \mathrm{sec}$. Bed elevation difference of canal and river was $6.3 \mathrm{~m}$ across the river. The aqueduct had nine barrels of dimension $7.0 \mathrm{~m} \times$ $6.9 \mathrm{~m}(W \times H)$ through which total discharge is flowed into the canal. Additionally, for validation of the developed methodology, nineteen datasets were obtained in the laboratory (Table 1).

\section{Methodology}

This study mainly focused on the fact that model predictions, in general, deviate from the actual predictions. This may be due to improper selection of either the model itself or assigning improper parametric values to the model parameters while estimating various quantities. Mostly, selection of improper model is not an issue. The main issue is involvement of uncertainty with the assigned parametric values. Hence, present study demonstrates that involvement of uncertainty in the assigned values of the model parameters results in deviation. The problem of scour prediction has been selected for the demonstration. In the present study, HEC-RAS model was used for hydrodynamic modelling and CSU model for hydraulic modelling. Uncertainty analysis was carried out for the parameters of the CSU model using Monte Carlo method of uncertainty. Figure 2 shows the algorithm of the methodology adopted in the present study.

\section{Hydrodynamic modelling}

The 1D model is governed by the basic assumption that water level across the cross-section is perpendicular to the flow ${ }^{19}$, and that the channel has longitudinal flow at uniform velocity ${ }^{20}$. The governing equations used in the numerical mode of HEC-RAS are 1D Saint-Venant equations for unsteady open channel flow (eqs (1) and (2)), which solve for scour and hydrodynamics flow conditions using an implicit finite difference methods ${ }^{10}$.

The continuity equation describes the conservation of mass.

$$
\frac{\partial A}{\partial t}+\frac{\partial S}{\partial t}+\frac{\partial Q}{\partial x}-q_{1}=0
$$

The momentum equation states that the rate of change in momentum is equal to the external forces acting on the system. 
Table 1. Description of laboratory data

\begin{tabular}{|c|c|c|c|c|c|c|}
\hline \multicolumn{4}{|c|}{$\begin{array}{l}\text { CSU parameters maintained during } \\
\text { experiment }\end{array}$} & \multirow[b]{2}{*}{ Flow depth (m) } & \multirow[b]{2}{*}{ Velocity (m/s) } & \multirow[b]{2}{*}{ Observed scour depth (m) } \\
\hline$K_{1}$ & $K_{2}$ & $K_{3}$ & $K_{4}$ & & & \\
\hline 1 & 1.2 & 1.1 & 0.34 & 0.42 & 0.17 & 0.11 \\
\hline 1 & 1.2 & 1.1 & 0.46 & 0.42 & 0.62 & 0.24 \\
\hline 1 & 1.2 & 1.1 & 0.51 & 0.43 & 0.88 & 0.34 \\
\hline 1 & 1.2 & 1.1 & 0.56 & 0.4 & 1.1 & 0.26 \\
\hline 1 & 1.2 & 1.1 & 0.59 & 0.4 & 1.26 & 0.3 \\
\hline 1 & 1.2 & 1.1 & 0.61 & 0.4 & 1.43 & 0.29 \\
\hline 1 & 1.2 & 1.1 & 0.64 & 0.4 & 1.64 & 0.32 \\
\hline 1 & 1.2 & 1.1 & 0.46 & 0.2 & 0.55 & 0.18 \\
\hline 1 & 1.2 & 1.1 & 0.5 & 0.2 & 0.72 & 0.24 \\
\hline 1 & 1.2 & 1.1 & 0.47 & 0.43 & 0.69 & 0.33 \\
\hline 1 & 1.2 & 1.1 & 0.36 & 0.49 & 0.25 & 0.14 \\
\hline 1 & 1.2 & 1.1 & 0.37 & 0.43 & 0.37 & 0.2 \\
\hline 1 & 1.2 & 1.1 & 0.44 & 0.38 & 0.58 & 0.19 \\
\hline 1 & 1.2 & 1.1 & 0.48 & 0.38 & 0.74 & 0.27 \\
\hline 1 & 1.2 & 1.1 & 0.55 & 0.38 & 1.05 & 0.29 \\
\hline 1 & 1.2 & 1.1 & 0.59 & 0.38 & 1.21 & 0.29 \\
\hline 1 & 1.2 & 1.1 & 0.61 & 0.38 & 1.37 & 0.29 \\
\hline 1 & 1.2 & 1.1 & 0.33 & 0.43 & 0.25 & 0.16 \\
\hline 1.1 & 1.2 & 1.1 & 0.4 & 0.19 & 0.5 & 0.12 \\
\hline
\end{tabular}

where $x$ is the distance along the channel, $t$ the time, $Q$ the flow discharge, $A$ the cross-sectional area, $S$ the ineffective flow area, $q_{1}$ the lateral inflow per unit distance, $V$ the average flow velocity, $S_{f}$ the slope friction and $g$ is the acceleration due to gravity. For detailed information about the HEC-RAS model, readers may refer to the HEC-RAS User's Manual ${ }^{21}$.

\section{Hydraulic analysis}

Analytical scour-depth computations based on parameters from 1D hydraulic analysis using HEC-RAS were performed. Various factors such as depth of flow, velocity of flow just upstream of the pier, width of the pier, gradation of bed material, shape of the pier, bed configuration and angle of attack of flow affecting the depth of local scour at the pier have been considered in the analysis. The HEC-RAS model has an in-built program for computation of scour depth around a pier under live-bed conditions using the CSU equation. Based on the given model inputs, HEC-RAS directly assigns values to various correction factors of the CSU equation and estimates scour depth. The type of CSU equation used in the HEC-RAS model is given below

$$
D=2.0 \times K_{1} \times K_{2} \times K_{3} \times K_{4} \times a^{0.65} y^{0.35} F^{0.43},
$$

where $D$ is the depth of the scour (m), $K_{1}$ the correction factor for pier nose shape, $K_{2}$ the correction factor for

Figure 2. Algorithm of the methodology used. 
Table 2. Percentage error in scour-depth prediction based on initial parameter value

\begin{tabular}{|c|c|c|c|c|}
\hline \multirow[b]{2}{*}{ Model parameters } & \multirow[b]{2}{*}{ Initial parameter value } & \multicolumn{2}{|c|}{ Scour depth (m) } & \multirow[b]{2}{*}{ Percentage error } \\
\hline & & Observed & Predicted & \\
\hline$K_{1}$ & 1 & & & \\
\hline$K_{2}$ & 1.3 & & & \\
\hline$K_{3}$ & 1.1 & & & \\
\hline$K_{4}$ & 1 & 3 & 3.8 & 26.6 \\
\hline$y$ & 2.5 & & & \\
\hline$V$ & 1.6 & & & \\
\hline$F$ & 0.32 & & & \\
\hline$\alpha$ & 2 & & & \\
\hline
\end{tabular}

angle of attack of flow, $K_{3}$ the correction factor for bed condition, $K_{4}$ the correction factor for armouring of bed material, $a$ the pier width (m), $y$ the flow depth directly upstream of the pier $(\mathrm{m})$, and $F$ is the Froude number directly upstream of the pier.

Based on the given model inputs, HEC-RAS by default directly assigns values to the various correction factors of the CSU equation. Comparison of the obtained result of HEC-RAS with the observed data collected from the field showed $26.6 \%$ deviation. Table 2 shows the percentage error in scour-depth prediction based on initial parameter values.

On examining the inputs provided and the output obtained, we found that there was further scope for improvement of the model result, particularly with the default assigned values of the correction factors. The deviation in the result clearly indicates the involved uncertainty with the default assigned values to the correction factors which are non-measured quantities. It is also possible with the HEC-RAS tool to assign the parametric values manually, if needed. Hence, in order to improve the model result, uncertainty analysis was carried out for the selected parameters which were obtained through sensitivity analysis.

\section{Uncertainty analysis}

In the present study, Monte Carlo method of uncertainty analysis was used based on decision tree suggested in the literature $^{16}$. This method considers any simulation that involves the use of random numbers. It generates uniform random parameter(s) ranges from the known upper and lower limits of the parameter. Only those parameters which are sensitive are considered in the analysis, while the others are kept constant ${ }^{22}$.

The input data collected from the study area were applied in the hydraulic model for estimating water depth at upstream of the pier as well the corresponding Froude number. Correlation-based sensitivity measures were adopted in order to check the sensitivity of the model parameters ${ }^{23}$. Parametric range of the sensitive parameters of the model was uniformly distributed to generate random numbers of the parameters. Then possible combinations of all parameters were formed. Uncertainty involved in the possible combinations of all parameters is evaluated using error analysis ${ }^{24}$, since parametric uncertainty arises due to the measurement of parameters in the field or through the experiment. Error propagation or uncertainty can be well handled with respect to the individual parameters by estimating their relative error. In case of optimizing parametric values, model efficiency can be evaluated but this will not address the uncertainty involved in the parameter. Hence, percentage error was used in this study to address the uncertainty ${ }^{24}$. The relationship for estimation of percentage error is given below

$$
\mathrm{Pe}=\frac{o-p}{o} * 100
$$

where $\mathrm{Pe}$ is the percentage error, $o$ the observed value and $p$ is the predicted value. Lower value of Pe indicates greater efficiency of the model.

\section{Results and discussion}

\section{Sensitivity analysis}

The CSU scour model (eq. (1)) consists of seven parameters, namely $K_{1}$ (correction factor for pier nose shape), $K_{2}$ (correction factor for angle of attack of flow), $K_{3}$ (correction factor for bed condition), $K_{4}$ (correction factor for armour bed) which depends on velocity and flow depth, $\alpha$ (pier width, m), $y$ (flow depth directly upstream of the pier) and $F$ (Froude number) which depends on velocity and flow depth. $K_{2}, K_{3}$ and $y$ are initially considered as uncertain parameters in this analysis. Close observation of these parameters revealed that a few of them could be excluded from the sensitivity analysis either due to their constant nature like pier width or such parameters which possess already considered parameters like Froude number.

The parameters excluded from the sensitivity analysis were $K_{1}, K_{4}, \alpha$ and $F$. Shape of the pier nose will not change throughout the life of a pier and hence, $K_{1}$ is a 
constant. $K_{4}$ and $F$ are functions of velocity and flow depth which are already considered in the analysis; hence these have been excluded from the sensitivity analysis. $\alpha$ also remains constant throughout the life of pier and therefore was excluded from the sensitivity analysis.

Sensitivity analysis, in this case, indicates the effect of small changes in these parameters producing large effects on scour depth. It was performed on the abovementioned uncertain parameters of the CSU equation and Table 3 provides the results in descending order of their sensitivity.

Table 3. Result of sensitivity analysis

\begin{tabular}{lcc}
\hline Parameter & Range & Sensitivity \\
\hline$K_{2}$ & $1-5$ & 2.63 \\
$K_{3}$ & $1.1-1.3$ & 2.52 \\
$y$ & $2-5(\mathrm{~m})$ & 0.17 \\
\hline
\end{tabular}
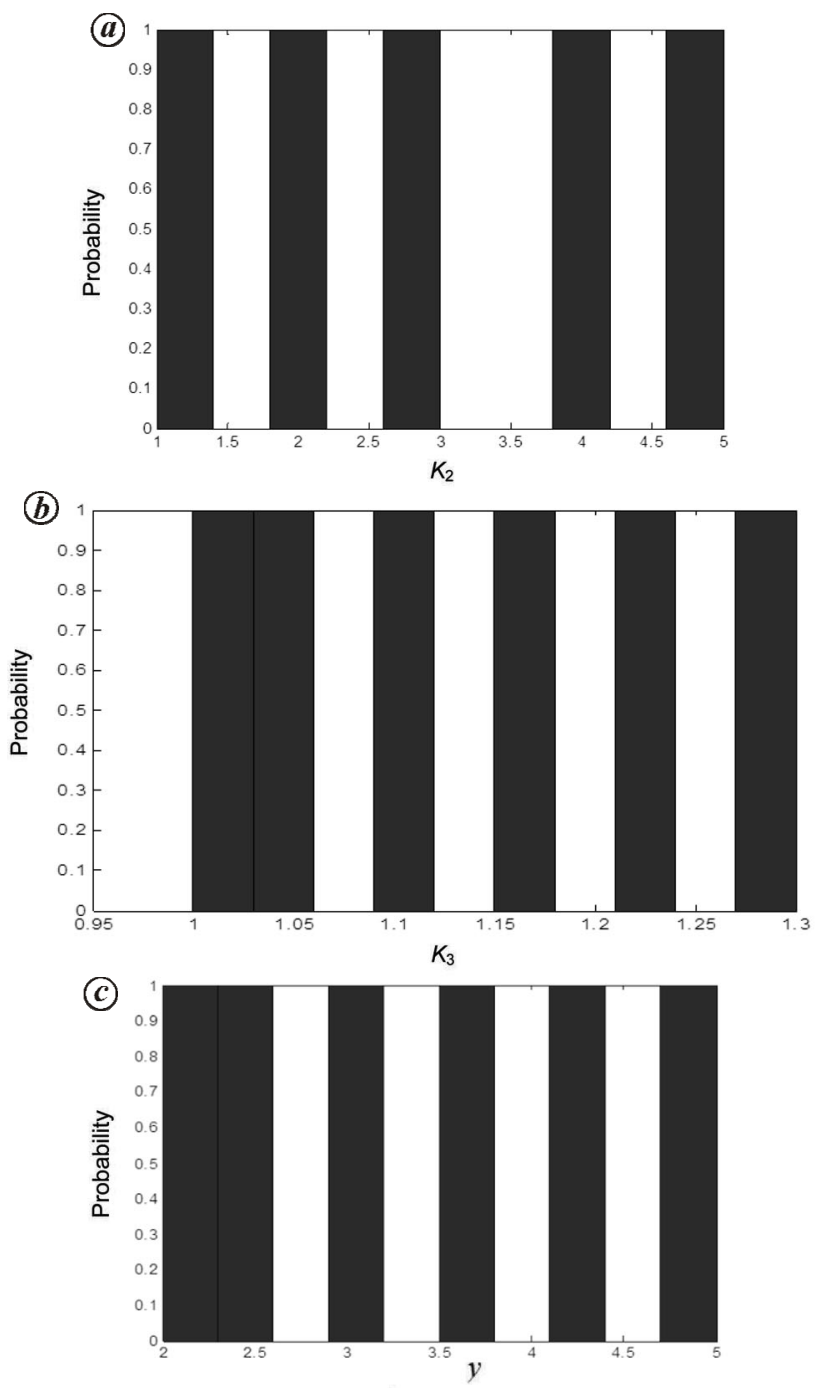

Figure 3. Uniform sampling of (a) $K_{2},(\boldsymbol{b}) K_{3}$ and (c) $y$.

\section{Sampling of parameters}

Sensitivity analysis helps in a way to reduce the number of parameters in the uncertainty analysis, which in turn helps in reducing computation cost. Parametric range of the identified sensitive parameters was distributed uniformly within the given range (Figure $3 a-c$ ). The reason for considering uniform distribution is that, each value of the parameter range has equal likelihood of occurrence ${ }^{14}$. Once the samples are uniformly distributed, combination of parameters is formed using MATLAB coding platform. These combinations may result in a huge number; in this case, it is more than 58 million combinations. Out of all parameter combinations, only those are retained which show model error $-5 \% \leq \mathrm{Pe} \leq+5 \%$. The retained parameter combinations are termed as behavioural

Table 4. Simulation results of Monte Carlo method

\begin{tabular}{|c|c|c|c|c|}
\hline \multirow[b]{2}{*}{ Model no. } & \multicolumn{3}{|c|}{ Uncertainty parameter } & \multirow[b]{2}{*}{ Percentage error } \\
\hline & $K_{2}$ & $K_{3}$ & $y$ & \\
\hline 1 & 1 & 1 & 2.6 & 4.88 \\
\hline 2 & 1 & 1 & 2.6 & 4.72 \\
\hline 3 & 1 & 1.12 & 2 & 3.55 \\
\hline 4 & 1 & 1.18 & 2 & -1.61 \\
\hline 5 & 1 & 1.24 & 2 & -3.78 \\
\hline 7 & 1.01 & 1.12 & 2 & 4.78 \\
\hline 8 & 1.01 & 1 & 2.6 & 3.42 \\
\hline 9 & 1.01 & 1.12 & 2.6 & 0.07 \\
\hline 10 & 1.03 & 1.12 & 5 & -4.27 \\
\hline 13 & 1.03 & 1 & 4.4 & 4.24 \\
\hline 14 & 1.03 & 1 & 3.2 & 2.74 \\
\hline 15 & 1.04 & 1.06 & 3.2 & -2.76 \\
\hline 16 & 1.04 & 1.12 & 3.2 & -2.26 \\
\hline 19 & 1.04 & 1.12 & 3.2 & 4.09 \\
\hline 20 & 1.04 & 1.12 & 3.2 & 0.45 \\
\hline 21 & 1.04 & 1.12 & 3.2 & -5.17 \\
\hline 25 & 1.04 & 1 & 4.4 & 4.21 \\
\hline 26 & 1.04 & 1.06 & 4.4 & -1.53 \\
\hline 27 & 1.05 & 1.12 & 4.4 & -3.27 \\
\hline 31 & 1.05 & 1 & 5 & 2.54 \\
\hline 32 & 1.05 & 1.06 & 5 & -3.29 \\
\hline 33 & 1.05 & 1 & 2.6 & -4.14 \\
\hline
\end{tabular}

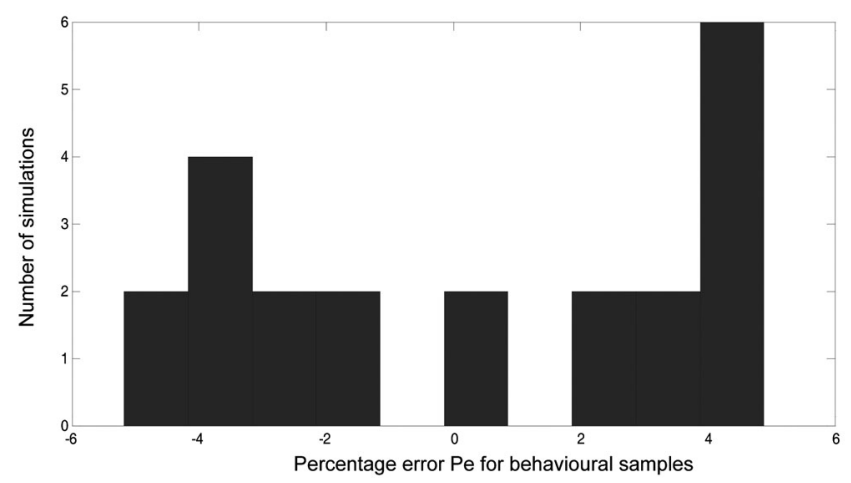

Figure 4. Simulation-wise percentage error (22 simulations). 


\section{RESEARCH ARTICLES}

samples and those which are discarded are known as the non-behavioural samples. In the present study, 22 such combinations were retained and model efficiency was calculated for each combination.

\section{Results of uncertainty}

Uncertainty analysis was carried out using the CSU model on the aqueduct, as mentioned earlier. The developed methodology was further applied to validate experimental data and results are presented in this section.

Uncertainty analysis using aqueduct data: The HECRAS hydraulic model of scour prediction and Monte Carlo method of uncertainty were coupled in MATLAB coding platform. Table 2 shows the scour model performance before uncertainty analysis. In the present study, percentage error is used as the objective function which is optimized. Twenty-two simulations were carried out for different sets of parameter combinations. The combination showing least error was chosen as the global optimum combination. Table 4 shows results of sample simulations. From the table, we can observe that model no. 9 has percentage error of 0.07 . Hence, parameter values of this model are considered to be global optimum values of parameters in the present study. It is possible to offer a variation of $\pm 5 \%$ to the globally optimized combination for getting optimum range of parameters. Error histogram was plotted and shown in Figure 4 for 22 simulations. It can be observed that none of the simulations have crossed over the $\pm 5 \%$ error and number of simulations are almost uniformly distributed within the error range of $\pm 5 \%$. Table 5 shows the tolerance range of global optimum combination (model no. 9). The table shows that percentage error is 9.3 for the lower-bound limit of the global optimum combination, whereas it is 2.3 in case of upper-bound limit. This analysis indicates that the scour model shows disparity in the estimations. Lowerlimit value of the global optimum parameter range was found to be relatively more sensitive than the higher-limit value. This indicates the necessity of assigning accurate parameter values to the model.

Validation of the developed methodology: The methodology developed was applied to the experimentally collected data for verification of their robustness in estimating true values of the parameters obtained.

From Figure 5 it can be seen that for the initial set of parameters the coefficient of determination for the experimental data is less than 0.7. Figure 6 shows results at the initial parametric values. From the figure, it can be seen that there is more deviation in the prediction of scour from the actual value. The developed algorithm was applied to experimental data and Figure 7 presents the results obtained. From the figure it can be seen that the predicted scour exactly matches the actual scour. Figure 7 also show the optimized parametric values. Parametric values are significantly increased from the initial values, which indicates that the CSU scour model underpreforms at initial parametric values. Hence, it can be concluded that the developed methodology also works for the any type of scour data. Further, it also confirmed the normal distribution of results (percentage error).

\section{Conclusion}

This study has successfully demonstrated the effect of predictive uncertainty and parameter sensitivity affecting model prediction capability of the well-known HEC-RAS 1D hydrodynamic scour prediction model. Uncertainty analysis drastically improved the predictive capability of the model by reducing the model error. In the present study, error had reduced from $26.6 \%$ to $0.07 \%$. Sensitivity analysis ranked the CSU model parameters in the order: $K_{2}, K_{3}$ and $y$. The angle of attack of flow was found to be the most sensitive parameter which significantly affected the scour due to its wake zone generating tendency around the pier. The bed condition was found to be the second most sensitive parameter due to its continuously changing nature. Flow depth directly upstream of the pier was found to be least sensitive to scour compared to the above two parameters, because of the fact that scouring is due to turbulence and not due to flow depth. It has also been concluded that, for any model, there is only a single combination of parameter values which can provide the most accurate model result. In general, the methodology suggested in this present study may be useful to improve

Table 5. Tolerance range $( \pm 5 \%)$ of global optimum combination (model 9)

\begin{tabular}{lccc}
\hline$K_{2}$ & $K_{3}$ & $y$ & Percentage error range \\
\hline $0.96-1.06$ & $1.06-1.17$ & $2.47-2.73$ & $9.3-2.3 \%$ \\
\hline
\end{tabular}

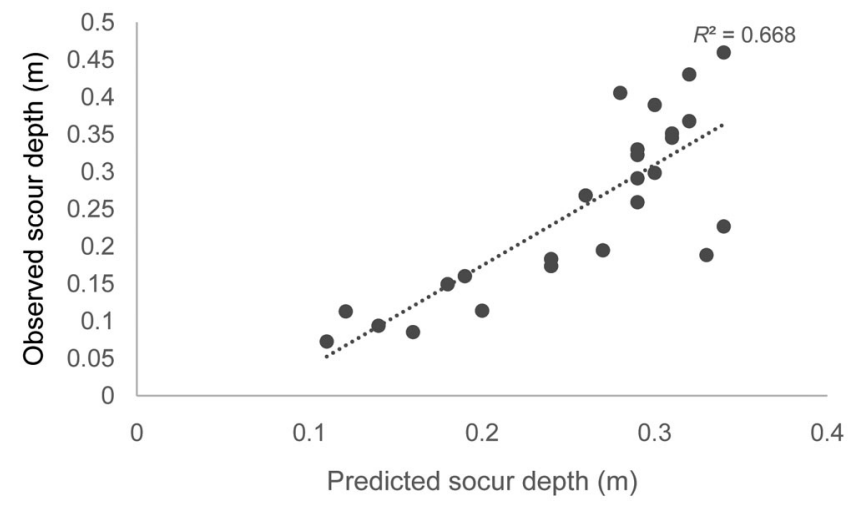

Figure 5. Coefficient of determination between observed and predicted scour depths at initial parametric values. 


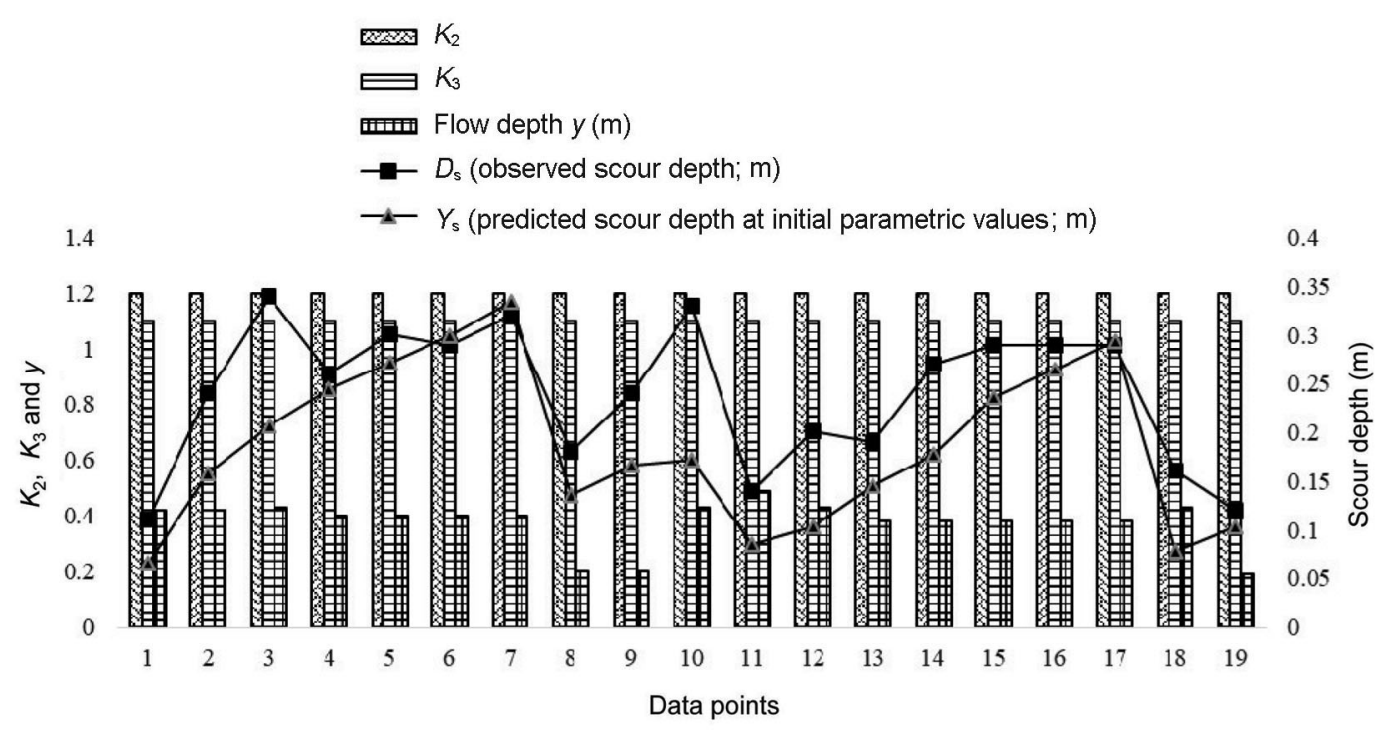

Figure 6. Estimation of scour depth and comparison with observed scour depth at initial parametric values.

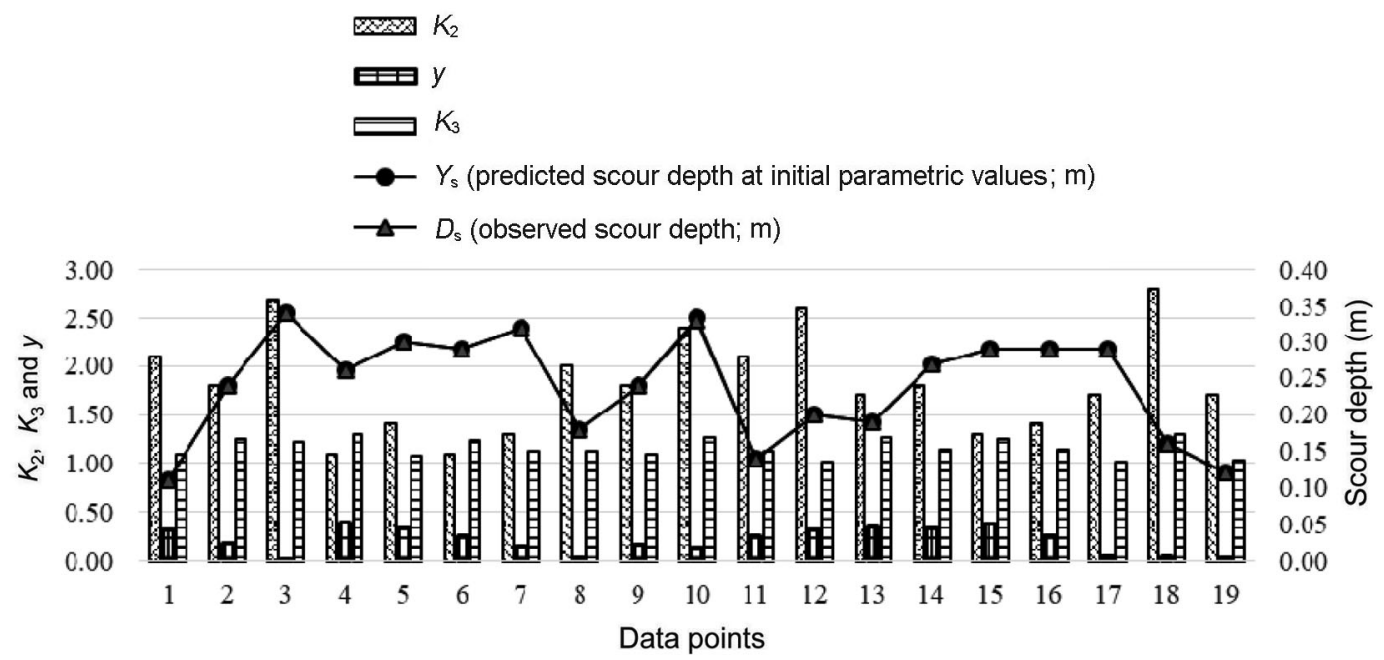

Figure 7. Predicted and observed scour depths at optimized parametric values.

the predictive capability of any model by obtaining global optimum values of parameters. Here, model no. 9 is recommended for scour prediction around the pier of the study area.

1. Breusers, H. N., Nicollet, G. and Shen, H. W., Local scour around cylindrical piers. J. Hydrol. Res., 1977, 15(3), 211-252.

2. Kumar, D., Yadav, H. L. and Himanshu, S. K., Estimation of scour depth around bridge piers by Using HEC-RAS. RACE-2011, 2011, pp. 421-425.

3. Kothyari, U. C., Garde, R. J. and Ranga Raju, K. G., Temporal variation of scour around circular bridge piers. J. Hydraul. Eng., ASCE, 1992, 118(8), 1091-1106.

4. Froehlich, D. C., Analysis of onsite measurements of scour at piers. In American Society of Civil Engineers National Conference on Hydraulic Engineering, Colorado Springs, CO, USA, 1988 , pp. $534-539$.
5. Jain, S. C. and Fischer, E. E., Scour around circular piers at high Froude numbers. Report No. FHWA-RD-79-104, US Department of Transportation, Federal Highway Administration, Washington, DC, USA, 1979.

6. Lacey, G., Stable channels in alluvium (includes appendices). In Minutes of the Proceedings of the Institution of Civil Engineers, 1930, vol. 229, pp. 259-292.

7. Melville, B. W., Pier and abutment scour: integrated approach. $J$. Hydraul. Eng., ASCE, 1997, 123(2), 125-136.

8. Richardson, E. V. and Davis, S. R., Evaluating scour at bridges. Hydraulic Engineering Circular No. 18(HEC-18), Report No. FHWA NHI 01-001, US Department of Transportation, Federal Highway Administration, Washington, DC, USA, 2001.

9. Landers, M. N. and Mueller, D. S., Channel scour at bridges in the United States, Report No. FHWA-RD-95-184, 1996.

10. Mohamed, T. A., Pillai, S., Noor, M. J. M. M., Ghazali, A. H., Huat, G. B. K. and Yusuf, B., Validation of some bridge pier scour formulae and models using field data. J. King Saud Univ., Eng. Sci., 2006, 19(1), 31-41. 
11. Johnson, P. A., Comparison of pier-scour equations using field data. J. Hydraul. Eng., ASCE, 1995, 121(8), 626-629.

12. Kuczera, G. and Parent, E., Monte Carlo assessment of parameter uncertainty in conceptual catchment models: the Metropolis algorithm. J. Hydrol., 1998, 211, 69-85.

13. Shamsudin, S., Dan'azumi, S. and Ab Rahman, A., Uncertainty analysis of HEC-HMS model parameters using Monte Carlo simulation. Int. J. Modell. Simul., 2011, 31(4), 279-286.

14. Beven, K. and Binley, A., The future of distributed models: model calibration and uncertainty prediction. Hydrol. Proc., 1992, 6, 279-298; doi:10.1002/hyp.3360060305.

15. Montanari, A. and Brath, A., A stochastic approach for assessing the uncertainty of rainfall-runoff simulations. Water Resour. Res., 2004, 40(1), 1-11.

16. Maskey, S., Guinot, V. and Price, R. K., Treatment of precipitation uncertainty in rainfall-runoff modelling: a fuzzy set approach Adv. Water Resour., 2004, 27(9), 889-898.

17. Shrestha, D. L., Kayastha, N. and Solomatine, D. P., A novel approach to parameter uncertainty analysis of hydrological models using neural networks. Hydrol. Earth Syst. Sci., 2009, 13(7), 1235 .

18. Pappenberger, F. and Beven, K. J., Ignorance is bliss: or seven reasons not to use uncertainty analysis. Water Resour. Res., 2006, 42(5), 1-8.
19. Wurbs, R. A., Computer Models for Water Resources Planning and Management, National Study of Water Management during Drought, Diane Publishing, 1997.

20. Uhlenbrook, S., Seibert, J. A. N., Leibundgut, C. and Rodhe, A., Prediction uncertainty of conceptual rainfall-runoff models caused by problems in identifying model parameters and structure. $H y$ drol. Sci. J., 1999, 44(5), 779-797.

21. Brunner, G. W., HEC-RAS River Analysis System, 1D-2D Modeling User's Manual, version 5.0. US Army Corps of Engineers, Hydrologic Engineering Center, Davis, 2016.

22. Tayefi, V., Lane, S. N., Hardy, R. J. and Yu, D., A comparison of one-and two-dimensional approaches to modelling flood inundation over complex upland floodplains. Hydrol. Process.: Int. J., 2007, 21(23), 3190-3202.

23. Saltelli, A. and Sobol, I. M., About the use of rank transformation in sensitivity analysis of model output. Reliab. Eng. Syst. Saf., 1995, 50(3), 225-239.

24. Taylor, J. R., An introduction to error analysis: the study of uncertainties in physical measurements, University of Science Books, Sausalito, California, 1997, pp. 92.

Received 2 November 2018; revised accepted 28 January 2020

doi: $10.18520 / \mathrm{cs} / \mathrm{v} 118 / \mathrm{i} 8 / 1227-1234$ 